\title{
Nuclear Security Training: A New Approach for Educating Nuclear Technology in Indonesia
}

\author{
Ferdiansjah $^{l}$, Susetyo Hario Putro ${ }^{l}$, Sihana $^{l}$, Widya $_{\text {Rosita }}{ }^{l}$, Faridah $^{l}$ \\ ${ }^{1}$ Department of Nuclear Engineering and Engineering Physics, Universitas Gadjah Mada, Yogyakarta-55281, Indonesia
}

\begin{abstract}
Indonesia has planned to erect Nuclear Power Plant for along time, but the government always postponed the plan due to the presence of anti-nuclear group that decreases the public acceptance. In addition, the public knowledge on nuclear technology is still low, since they only get in the last month before finish their study in high school. The socialization of nuclear technology done by government body could not significantly increase the public acceptance, since the knowledge and confidence on nuclear technology among the government employee is also low. The recent issue regarding to nuclear security give a new opportunity in socializing strategy. Department of Nuclear Engineering and Engineering Physics Universitas Gadjah Mada (UGM) as the only one university in Indonesia offering nuclear engineering education had conducted several nuclear security training for specific people who had been not targeted in previous socialization programs. The training done in collaboration with National Nuclear Energy Regulatory Body (BAPETEN) of Indonesia was conducted in Batam, Surabaya and Jakarta. Almost 20 people coming from police department, national coast guard, custom agency, etc attended in the training. Training materials consist of introduction on nuclear technology, introduction on nuclear security, physical protection system, radiation detection, transport security, etc. Pre-test and post-test were done to know their improvement. This was first time for most of participants to get nuclear technology knowledge. Based on the survey their knowledge was significantly improved. They felt that the training was valuable for them to know the benefit and risk of nuclear technology. We believe that it could increase the public participant and acceptance on utilizing nuclear technology in Indonesia.
\end{abstract}

Keywords - education, nuclear security, training

NOMENCLATURE

UGM - Universitas Gadjah Mada

BAPETEN - National Nuclear Energy Regulatory Body of Indonesia

BATAN - National Nuclear Energy Agency of Indonesia

I-CoNSEP - Indonesian Centre of Excellence of Nuclear Security and Emergency Preparedness

CSCA - Center for Security Culture and Assessment

CITS - Center for International Trade and Security

UGA - University of Georgia, USA

NSS - Nuclear Security Series

PDC - Professional Development Course

KCL - King's College London

RPM - Radiation Portal Monitor

PRD - Personal Radiation Detector

RID - Radionuclide Identification Detector

NSD - Neutron Search Detector

ITDB - International Threat Data Base 


\section{Introduction}

Indonesia has planned to build Nuclear Power Plant for along time, but the government always postpones the plan due to the presence of anti-nuclear group that decreases the public acceptance. In addition, the public knowledge on nuclear technology is still low, since they only get in the last month before finish their study in high school. The socialization of nuclear technology done by government body could not significantly increase the public acceptance, since the knowledge and confidence on nuclear technology among the government employee is also low. Susetyo Hario Putero, Haryono Budi Santosa and Widya Rosita (2012) said that proactively improving a community's knowledge about nuclear technology is a one of key success factor to opening a public dialogue on the first NPP in Indonesia [1]. They found that nuclear energy technology is only introduced, as part of the radiochemistry topic, in last two months before a student graduates from senior high school. In addition, most of the engineering and science education programs in higher education level are unrelated to nuclear science and technology (more than 96\%).

The recent issue regarding to nuclear security addressed by IAEA under IAEA Nuclear Security Plan 2010 - 2013 give a new opportunity in socializing strategy for specific people who had been not targeted in previous socialization programs. This paper would like to describe the new approach of Department of Nuclear Engineering and Engineering Physics Universitas Gadjah Mada (UGM) as the only one university in Indonesia offering nuclear engineering education to socialize nuclear technology in Indonesia.

\section{Current nuclear technology in indonesia and its threats}

Since 1965, nuclear technology is known and utilized nuclear technology in Indonesia, especially for medical, food and industrial purposes. But, until know, the government is always postponed their plan to build the first NPP due to the protester, eventhough in national energy policy for 2006-2025, NPP is planned to supply about $2 \%$ of the national energy demand. It is believed that most of Indonesian has no adequate knowledge of nuclear technology got from formal education as mentioned before. Their knowledge on "nuclear" word is mostly influenced by several negative and improper things, such as the atomic bomb, human radiation experiments, and the genetic mutations pictured as "monster" or "superhero" in popular comics.

For increasing the knowledge, institutions related to nuclear technology (BAPETEN, National Nuclear Energy Agency of Indonesia/BATAN, UGM, etc,) have conducted several activities, such as educating community leaders, seminars, "Atom day", community emporwent, etc. UGM itself has four targets in educating people, i.e. schools student, rural people, urban communities and scientific community. There were some positive impacts from the target groups [2]. Their knowledge on risks and benefits of nuclear technology is more balance.

The recent issue in utilization of nuclear technology is nuclear security. Because it is still new issue in Indonesia and hence the knowledge for securing radioactive material is questioned. In the other hand, several terrorist acts had attacked people in Indonesia. Last January, suicide bombing and gun firing done were attacked Jakarta and killed seven people including the terrorists. Eventhough, radionuclide did not present in the attacks, but the possibility could not be neglected.

Nuclear security issue is not only related to the terrorism, but also could be associated to the international nuclear materials transport either sea or air transports. Since Indonesia is a strategic position between Asia and Australia, Pacific Ocean and Hindia Ocean, the risk in nuclear traffic and trade from one country to other through Indonesia territorial is high. Security risk could also be escalated resulted from the escalation of regional security risk. OECD/IEA said that there are 6 power reactors proposed to be erected in Southeast Asia countries region to supply their electricity demands [3].

For overcoming the security issue, BAPETEN has initiated Indonesian Centre of Excellence of Nuclear Security and Emergency Preparedness (I-CoNSEP) for coordinating all activities related to the nuclear security. UGM has signed a Memorandum of Undertanding with BAPETEN to serve as a national centre for nuclear security education coordinated under I-CoNSEP [4]. In order to build national nuclear security capacity, UGM actively promotes and educates nuclear security to community by maximizing internal resources and external networking.

BATAN actively builds the security culture among their staffs as well as safety culture. They also conducted nuclear security culture self-assessment based on IAEA methodology as the first pilot project in the world in 2012 . It was supported by IAEA and experts from CITS-UGA, USA. BATAN has decided to establish a Center for Security Culture and Assessment (CSCA) on 29 September 2014, as an expert and training hub nationally, regionally and internationally in cooperation with the IAEA and CITS-UGA [5]. The center succesfully conducted the second self-assessment in 2015.

\section{Nuclear security training in indonesia and its impacts}

The committment of UGM to overcome nuclear security issue is an implementation of the vission to become one of center for excellent in nuclear engineering education in South East Asia region. To realize it, UGM has conducted international nuclear security education professional development course (PDC) based on NSS-12 in collaboration with Centre for Science \& Security Studies, King's College London (KCL) in 2014 and 2015. Based on the experience in running PDC, UGM conducted some nuclear security trainings in collaboration with BAPETEN to build national nuclear security capacity. 
There were two type of trainings. The first was four days training to train Front Liner Officer (Harbor Officer, Police Officer and National Ocean Guard Officer) in two big harbors (Batam and Surabaya). Some hospital staffs, custom officers and East Java Disaster Management Authority staffs also joined in Surabaya training. The second was one day training for management team who will make some rules or decisions in nuclear area.

The materials for first type were not only nuclear security related materials (introduction on nuclear security, physical protection system, transport security, etc.), but also consisted of introduction on nuclear technology (basic of ionizing radiation, radiation effect, radiation units, safety principle and radiation detection) in order to build a strong foundation in understanding nuclear security. Materials were delivered using multiple delivery methods that are classical, field visit, case study, watching related videos, practical works and table top exercise to keep the enthusiasm of trainees.

The participants in second type training were higher profile persons than the first type. Therefore, materials were related to the security policy, international and national regulations, and introduction to I-CoNSEP that were delivered by using classical method. Pre-test and post-test were done to know their improvement by comparing the knowledge before and after attending training.

\section{Research Methodology}

The impact of the training in nuclear security will be measured by two procedures :

1. Pre test question

2. Post test question

Pretest questions are intended to gain information about existing knowledge of the participants for several topics related to nuclear security. This information is very important so in the future the appropriate level of training could be tailored.

Post test questions could be used to measure the impact of training for the participants. The data is very important because it could measure the increase of knowledge after training is completed.

The score that is used to measure the level of knowledge varies from 0 to 7 , where 0 denotes no prior knowledge of the subject and 7 shows the full knowledge regarding with the subject. Impact could be determined by comparing an increase on the level of knowledge to the initial level of knowledge

\section{Results and discussion}

Survey in first type training shows that about $20 \%$ of trainees had already haven basic knowledge on nuclear security. They already known how to use radiation detector. But, only $6 \%$ of 26 trainees in Batam and $15 \%$ of 17 trainess in Surabaya had a good understand. Therefore, the training was the first event to know not only nuclear security but also nuclear technology for the most participants, although dealing with radiation should be a part of their job by national regulations. They looked enthusiastic to learn and want to attend in next training. Survey in second type training for higher profile people confirmed that advanced national nuclear security training is needed.

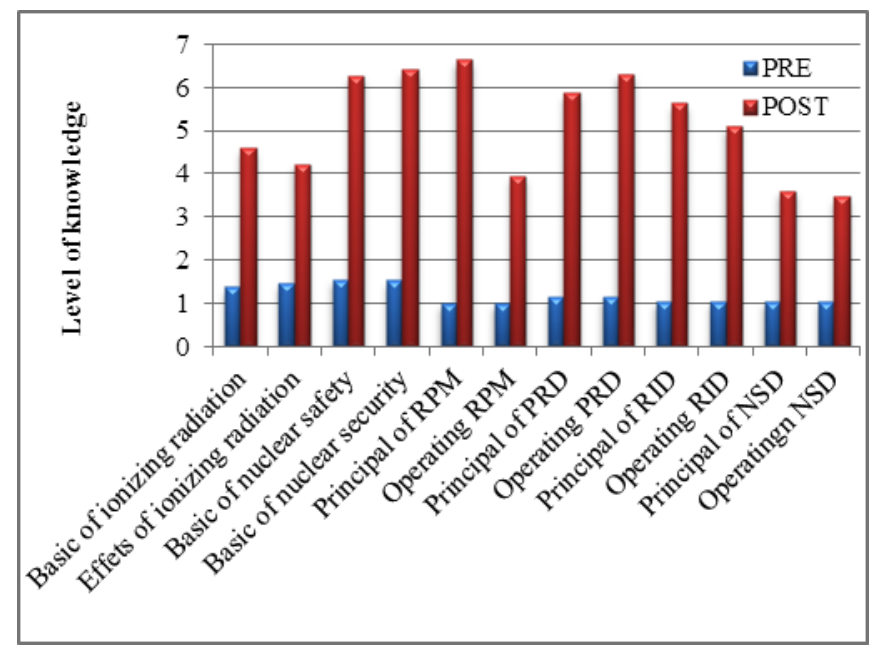

(a)

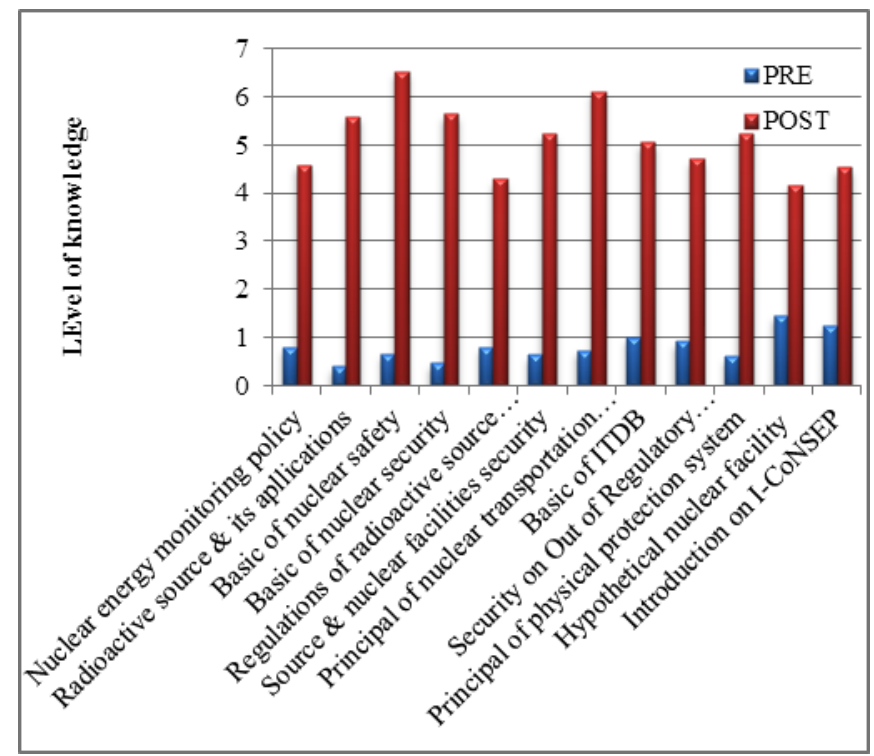

(b)

Figure 1. Pre-test and post-test results in (a) Batam and (b) Surabaya.

Fig. 1 shows that their knowledge was significantly improved from below level 2 to upper level 4 (average). In some materials (basic safety, basic security, principal of radiation detector, principal of physical protection, and principal of security in transport) the improvement reached more than level 6 . It was believed that the delivery method that were used for those topics (case study, practical work and table top exercise) affected the improvement. The results in Surabaya was better than Batam one, because there was some revision on delivery method based on Batam's experience. The improvements on the knowledge of Neutron Search Detector (NSD) were lowest, because there was no neutron source for practicing, and hence the trainees was difficult to 
understand. But, in general, we could say that trainings succesfully improved their knowledge on nuclear security.

Discussion during training, either in class or break, was not only limited to nuclear security, but also nuclear technology in common, especially that related to nuclear safety in their job activities. Nuclear safety and waste management were favorite topics to be discussed. The important thing in training is how the trainers could improve their self-confidence in dealing with radioactive materials by knowing the benefit and risk of nuclear technology. We believe that it could increase the public participant and acceptance on utilizing nuclear technology. Comments and impressions from participants written in post-test show that the training was valuable for them. It is proven when trained National Ocean Guard Officers in Batam in collaboration with BAPETEN arrested an international ship which presumed to bring illegal uranium across Batam area.

\section{Conclusions}

Nuclear security training was first time for most of participants to get nuclear technology knowledge. Based on the survey their knowledge was significantly improved. They felt that the training was valuable for them to know the benefit and risk of nuclear technology. We believe that it could increase the public participant and acceptance on utilizing nuclear technology in Indonesia.

\section{Acknowledgment}

The authors gratefully acknowledge the support of the Department of Nuclear Engineering and Engineering Physics, Universitas Gadjah Mada. We also thank BAPETEN for cooperation. Support from Partnership for Nuclear Security (PNS)-USA and CRDF Global in presenting this paper are acknowledge.

\section{References}

[1] Susetyo Hario Putero, Haryono Budi Santosa and Widya Rosita, 2012, Challenge in the Public Acceptance and Cooperation on the Verge of Building the First Nuclear Power Plant in Indonesia, Proc. of the 2012 20th International Conference on Nuclear Engineering Collocated with the ASME 2012 Power Conference, ASME, Anaheim.

[2] Widya Rosita, Anung Muharini, Ester Wijayanti, Susetyo Hario Putero, 2015, The Role of Universitas Gadjah Mada on Forming Public's Perception about Nuclear in Indonesia through Community Empowerment Programs, Paper presented in 2015 Women in Nuclear Annual Meeting, Vienna.

[3] Asia's Nuclear Energy Growth, Available on http://www.world-nuclear.org/ (accessed on 2nd April 2014).

[4] Susetyo Hario Putero, et.al., 2014, The Role of Universitas Gadjah Mada in the Recent Global Nuclear Security, Proc. of the 3rd Applied Science for Technology Application, ASTECHNOVA 2014 International Energy Conference, Yogyakarta.
[5] Anhar R. Antariksawan and Khairul, 2015, Nuclear Security Culture and Assessment: BATAN's Experience, Paper presented in ASTECHNOVA 2015 International Energy Conference, Yogyakarta. 